\title{
Association between Antioxidant Enzyme Activities and Enterovirus-Infected Type 1 Diabetic Children
}

\author{
Adel Abdel-Moneim ${ }^{\mathrm{a}}$ Waled M. El-Senousy ${ }^{\mathrm{b}}$ Mahmoud Abdel-Latif ${ }^{\mathrm{c}}$ \\ Rehab G. Khalilc \\ ${ }^{a}$ Molecular Physiology Division, Department of Zoology, Faculty of Science, Beni-Suef University, Beni-Suef, Egypt; \\ ${ }^{b}$ Department of Water Pollution Research, Environmental Research Division, National Research Centre (NRC), Dokki, \\ Cairo, Egypt; ' Immunity Division, Department of Zoology, Faculty of Science, Beni-Suef University, Beni-Suef, Egypt
}

\section{Significance of the Study}

- This study revealed that children with type 1 diabetes (T1D) infected with Enterovirus (EV) show a marked decrease in glutathione peroxidase, superoxide dismutase, and catalase activity, and a noticeable elevation in C-reactive protein compared to noninfected diabetic children. Our results confirm an association of EV infection with the inflammation and $\beta$ cell damage seen in T1D, and suggest that antioxidant supplementation can play a protective role.

\section{Keywords}

Type 1 diabetes · Enterovirus · Antioxidant enzymes ·

Diabetic children

\begin{abstract}
Objective: To examine the effect of infection with Enterovirus (EV) in children with type 1 diabetes (T1D) on the activities of serum antioxidant enzymes in diabetic and nondiabetic controls. Subjects and Methods: Three hundred and eighty-two diabetic and 100 nondiabetic children were tested for EV RNA using reverse transcriptase (RT)-PCR. The activities of serum superoxide dismutase (SOD), glutathione peroxidase (GPx), and catalase (CAT) were also estimated in diabetic patients infected with EV (T1D-EV+), those not infected with EV (T1D-EV-), and in nondiabetic controls. $\boldsymbol{R e}$ sults: The frequency of EV was higher in diabetic children
\end{abstract}

\begin{tabular}{ll}
\hline KARGER & $\begin{array}{l}\text { (c) 2018 The Author(s) Karger } \\
\text { Published by S. Karger AG, Basel Open access }\end{array}$ \\
E-Mail karger@karger.com & $\begin{array}{l}\text { This is an Open Access article licensed under the Creative Commons } \\
\text { Attribution-NonCommercial-4.0 International License (CC BY-NC) } \\
\text { (http://www.karger.com/Services/OpenAccessLicense), applicable to } \\
\text { the online version of the article only. Usage and distribution for } \\
\text { commercial purposes requires written permission. }\end{array}$
\end{tabular}

$(100 / 382 ; 26.2 \%)$ than in healthy controls (0/100). Levels of fasting blood glucose (FBG), glycosylated hemoglobin $\left(\mathrm{HbA}_{1 \mathrm{c}}\right)$ and $\mathrm{C}$-reactive protein (CRP) were significantly higher but C-peptide was significantly lower in diabetic children than in controls. CRP levels were higher in the T1D-EV+ group than in the T1D-EV- group, and higher in all diabetic children than in nondiabetic controls. The activities of the antioxidant enzymes GPx, SOD, and CAT decreased significantly in diabetic children compared to in controls. Moreover, the activities of the enzymes tested were significantly reduced in the T1D-EV+ group compared to in the T1D-EVgroup. Conclusion: Our data indicate that EV infection correlated with a decrease in the activity of antioxidant enzymes in the T1D-EV+ group compared to in the T1D-EVgroup; this may contribute to $\beta$ cell damage and increased inflammation.

(c) 2018 The Author(s)

Published by S. Karger AG, Basel
Adel Abdel-Moneim

Molecular Physiology Division, Department of Zoology

Faculty of Science, Beni-Suef University

Salah Salim St., 62511, Beni-Suef (Egypt)

E-Mail adel_men2020@yahoo.com and adel.hassan@science.bsu.edu.eg 
Table 1. Detection of serum Enterovirus (EV)-positive samples in children with type 1 diabetes (T1D)

\begin{tabular}{lcccc}
\hline & $N$ & EV RNA-positive, $n(\%)$ & \multicolumn{2}{l}{ Gender, $n(\%)$} \\
\cline { 4 - 5 } & & & male & female \\
\hline Controls (nondiabetics) & 100 & $0(0)$ & $0(0)$ & $0(0)$ \\
T1D children (total) & 382 & $100(26.2)$ & $60(60)$ & $40(40)$ \\
$\quad$ Newly diagnosed & 185 & $54(29.1)$ & $30(55.5)$ & $24(44.5)$ \\
Previously diagnosed & 197 & $46(23.3)$ & $30(65.2)$ & $16(34.8)$ \\
\hline
\end{tabular}

Type 1 diabetes (T1D) results from a selective immune-mediated destruction of the pancreatic $\beta$ cells in subjects carrying permissive human leukocyte antigen genotypes. The rapidly increasing incidence of T1D suggests that nongenetic factors are also involved in its etiology [1]. In Egypt, the incidence of T1D is reported as $8 / 100,000$ people/year in children aged $\leq 14$ years [2]. T1D is characterized by dysregulated blood glucose caused by $\beta$ cell insufficiency accompanied by elevated glycosylated hemoglobin $\left(\mathrm{HbA}_{1 \mathrm{c}}\right)$ [3].

Oxidative stress is a widely accepted participant in the pathogenesis of both $\beta$ cell dysfunction and the development of T1D and its complications [4]. The main antioxidant enzymes are serum superoxide dismutase (SOD), catalase (CAT), and glutathione peroxidase (GPx) [5]. In addition, GPx in mitochondria and lysosomes catalyzes the conversion of hydrogen peroxide to water and oxygen [6]. The other antioxidant enzymes include glutathione (GSH) reductase, GSH S-transferase, peroxiredoxin, thioredoxin, and thioredoxin reductase [7]. $\beta$ Cells express low levels of the antioxidant enzymes SOD, CAT, and GPx, and thereby increase their susceptibility to oxidative stress [8]. Oxidative stress occurs when the generation of reactive oxygen species (ROS) overcomes the scavenging abilities of antioxidants, and it may be mediated by a genetic lack of antioxidant enzymes as well as environmental triggers like viral infections [9]. In T1D, evidence implicates the role of ROS in impaired $\beta$ cell function that is caused by autoimmune reactions, cytokines, and inflammatory proteins [4].

Epidemiological studies have demonstrated higher rates of Enterovirus (EV) infection in patients with T1D than in nondiabetic controls $[10,11]$. EV antigen expression has been detected by immunohistochemistry in the pancreatic $\beta$ cells of patients with recent-onset T1D [12]. EV capsid protein (VP1) was detected by immunostaining in $61 \%$ of the pancreatic autopsy specimens from patients with recent-onset T1D [13]. Collectively, these data suggest that there are certain EVs that play an etiological role in T1D. Evidence for the association of EV infection with TD1 has been reported in Egyptian patients [2]. The aim of this study was to determine the circulating levels of antioxidant enzymes in the serum of diabetic and nondiabetic children, in order to explore the relationship between T1D-associated EV and antioxidant enzymes.

\section{Materials and Methods}

\section{Patients}

This study included 382 children with T1D and 100 healthy, nondiabetic controls who visited the Endocrine and Diabetes Institute of Cairo University during the period from October 2013 to September 2014. The age of the diabetic children ranged from 2 to 16 years (mean $9.8 \pm 2.9$ years) and that of nondiabetic control children from 3 to 14 years (mean $9.1 \pm 2.7$ years). Both control and diabetic children were matched in sex and age and were free of infectious diseases, autoimmune disorders, and allergies, as confirmed by clinical and laboratory investigations made by physicians at the Institute. Written informed consent was provided for all children and the study was approved by the relevant ethics committee. Additionally, the study protocol conformed to Egyptian National Guidelines and was performed in accordance with the Declaration of Helsinki and Good Clinical Practice guidelines. Venous blood $(5-\mathrm{mL})$ samples were collected in serum tubes (BectonDickinson, Franklin Lakes, NJ, USA) by venous puncture using a 21 -gauge needle. Serum samples were obtained by centrifugation at $4{ }^{\circ} \mathrm{C}$ and $4,000 \mathrm{rpm}$ for $10 \mathrm{~min}$, and were then kept at $-80^{\circ} \mathrm{C}$.

\section{RT-PCR for Enterovirus}

Viral RNA extraction was performed using $\mathrm{BIOZOL}^{\circledR}$ total RNA extraction reagent (Bioflux, Tokyo, Japan). Nested RT-PCR was performed according to the procedure reported by Puig et al. [14], using the primers Ent 1: 5-CGG TAC CTT TGT ACG CCT GT-3 and Ent 2: 5-ATT GTC ACC ATA AGC AGC CA-3 for the first round of PCR, and neEnt 1: 5-TCC GGC CCC TGA ATG CGG CTA-3 and neEnt 2: 5-GAA ACA CGG ACA CCC AAA GTA-3 for the second round, to amplify the 138-bp fragment. PCR products $(10 \mu \mathrm{L})$ were analyzed by electrophoresis on $3 \%$ agarose gels (PanReac Química, Spain). Briefly, the reaction mixture for reverse transcription had a total volume of $10 \mu \mathrm{L}$ and contained $5 \mu \mathrm{L}$ of the nucleic acids extracted plus IX PCR amplification buffer, dNTPs at $200 \mu \mathrm{M}$ each, $200 \mathrm{U}$ of MMULV (Thermo Scientific), and $2.5 \mu \mathrm{M}$ of the external primer Ent2. The reaction mixture was incubated at 
Fig. 1. a FBG levels in the plasma. b $\mathrm{HbA}_{1 \mathrm{c}}$ levels in the serum. c C-peptide levels in the serum. d CRP levels in the serum (means \pm SEM). ${ }^{* * *} p<0.001$.
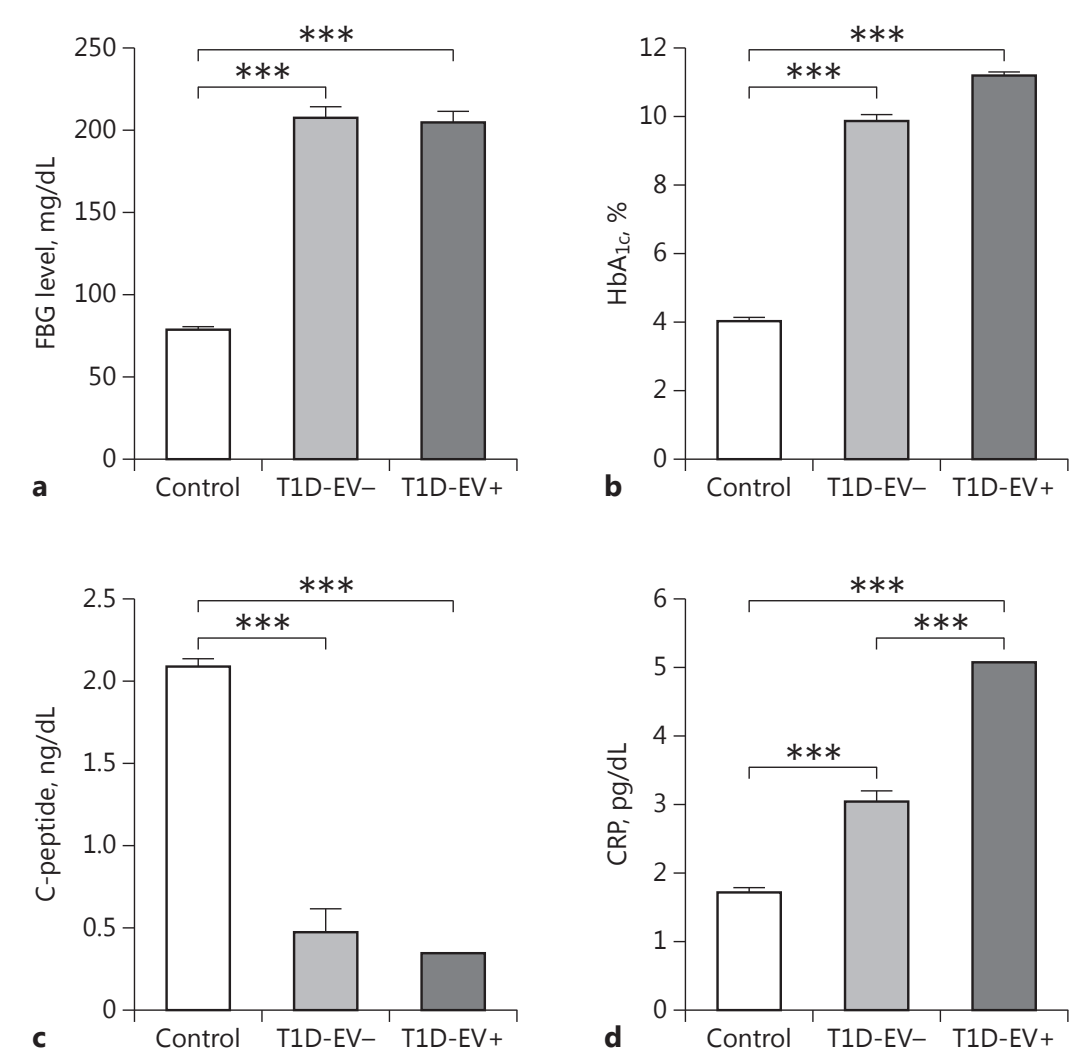

$95^{\circ} \mathrm{C}$ for $5 \mathrm{~min}$ before the addition of the enzyme and a ribonuclease inhibitor (RNasin; Promega, Mannheim, Germany]). The temperature cycle was set for $30 \mathrm{~min}$ at $42^{\circ} \mathrm{C}$ and $5 \mathrm{~min}$ at $95^{\circ} \mathrm{C}$. For the first round of PCR, the temperature amplification was carried out in a $50-\mu \mathrm{L}$ reaction mixture containing $50 \mathrm{~mm} \mathrm{KCl}, 10 \mathrm{~mm}$ Tris- $\mathrm{HCl}$ ( $\mathrm{pH} 9.0$ at $25^{\circ} \mathrm{C}$ ), $1.5 \mathrm{mM} \mathrm{MgCl}_{2}, 0.01 \%$ gelatin (wt/vol), $0.1 \%$ Triton $\mathrm{X}-100,200 \mu \mathrm{m}$ dNTPs, $0.5 \mu \mathrm{m}$ for each primer, and $2 \mathrm{U}$ of Taq DNA polymerase (Thermo Scientific). The first cycle of denaturation was carried out for $4 \mathrm{~min}$ at $94^{\circ} \mathrm{C}$. The conditions for amplification consisted of denaturing at $92^{\circ} \mathrm{C}$ for $90 \mathrm{~s}, 55^{\circ} \mathrm{C}$ for $90 \mathrm{~s}$, and $72^{\circ} \mathrm{C}$ for $120 \mathrm{~s}$. Nested PCR was done for 30 new cycles with the same thermal profile, using $0.20 \mu \mathrm{M}$ of neEnt 3 and neEnt 4 primers.

Based on the RT-PCR results, the children were divided into 3 study groups ( $n=100$ in each): (1) T1D-EV+ (60 males and $40 \mathrm{fe}-$ males; age range $2-16$ years, mean \pm SD $9.5 \pm 3.3$ years), (2) T1D-EV( 56 males and 46 females; age range $3-15$ years, mean $9.5 \pm 3.1$ years), (3) healthy controls, i.e., nondiabetics (50 males and 50 females; age range $3-14$ years, mean $9.1 \pm 2.7$ years). The T1D-EV + and T1D-EVgroups were further divided into newly $(<1$ year) and previously $(>1$ year) diagnosed children (according to Maha et al. [2]).

\section{Laboratory Assessment}

Fasting blood glucose (FBG) was measured in the plasma samples of both diabetic and control children, and then estimated using the commercial kit (SPINREACT, Spain). $\mathrm{HbA}_{1 \mathrm{c}}$ ELISA kits were purchased from MyBiosource (San Diego, CA, USA), the C- peptide ELISA kits from DRG Diagnostics (Marburg, Germany), and the C-reactive protein (CRP) ELISA kits from R\&D Systems. Serum SOD, GPx, and CAT activities were measured using reagent kits purchased from OXIS International, Inc., USA. All procedures were performed according to the manufacturers' instructions.

\section{Statistical Analysis}

Analysis of data was carried out using an IBM computer utilizing the Statistical Program for Social Sciences (v23.0; Chicago, IL, USA). All statistical comparisons were made by means of the oneway ANOVA test. Results were articulated as mean \pm standard error (SEM) and $p<0.05$ was considered significant.

\section{Results}

\section{Frequency of EV RNA in Serum}

A higher frequency of EV RNA was found in children with T1D $(100 / 382,26.2 \%)$ than in healthy controls (nondiabetic) children (0/100). There was a higher frequency in males $(60 \%)$ than in females $(40 \%)$. The frequency of RNA was higher in newly diagnosed EV infection (54; $29.1 \%)$ than in previously diagnosed infection $(46 ; 23.3 \%)$ (Table 1). 
Table 2. Levels of GPx, SOD, and CAT enzymes in control subjects and in diabetic children with or without Enterovirus infection

\begin{tabular}{llcl}
\hline $\begin{array}{l}\text { Antioxidant } \\
\text { enzymes }\end{array}$ & Group & & \\
\cline { 2 - 4 } & control & T1D-EV- & T1D-EV+ \\
\hline $\begin{array}{l}\text { GPx, mmol/mL } \\
\quad \text { Range }\end{array}$ & $70.30-88.1$ & $28.30-37.2$ & $15.40-29.4$ \\
$\quad$ Mean \pm SD & $77.71 \pm 4.04$ & $31.76 \pm 1.82^{\mathrm{a}}$ & $22.59 \pm 5.04^{\mathrm{b}}$ \\
SOD, U/mL & & & \\
$\quad$ Range & $8.10-10.80$ & $4.10-6.10$ & $1.30-2.80$ \\
$\quad$ Mean \pm SD & $9.20 \pm 0.73$ & $4.81 \pm 0.48^{\mathrm{a}}$ & $2.05 \pm 0.26^{\mathrm{b}}$ \\
CAT, U/mL & & & \\
$\quad \begin{array}{l}\text { Range } \\
\text { Mean } \pm \text { SD }\end{array}$ & $198.80-241.20$ & $106.3-129.20$ & $72.60-98.60$ \\
& $216.20 \pm 7.85$ & $119.30 \pm 5.85^{\mathrm{a}}$ & $88.07 \pm 6.39^{\mathrm{a}, \mathrm{b}}$ \\
\hline
\end{tabular}

T1D-EV-/EV+, type 1 diabetes without/with Enterovirus infection; SOD, superoxide dismutase; GPx, glutathione peroxidase; CAT, catalase.

a Statistically significant difference between controls and T1DEV- or T1D-EV+ children.

${ }^{\mathrm{b}}$ Statistically significant difference between the T1D-EV+ and the T1D-EV- groups.

Serum Levels of FBG, $\mathrm{HbA}_{10}$ and C-Peptide

The mean levels of FBS and $\mathrm{HbA}_{1 \mathrm{c}}$ in diabetic children were significantly higher than in nondiabetic controls $(p<0.001$; Fig. 1a, b). C-peptide concentrations were significantly lower in T1D-EV- children than in healthy controls, but not significantly different in T1D- EV- and T1D-EV+ children (Fig. 1c). Moreover, CRP levels were significantly elevated in both the T1D-EV+ and T1D$\mathrm{EV}$ - groups compared to in nondiabetic controls $(p<$ 0.001 ; Fig. 1d), and significantly higher in T1D-EV+ children $(p<0.001)$ than in T1D-EV- children.

\section{Levels of Antioxidant Enzymes}

The levels of GPx, SOD, and CAT were found to be decreased significantly in the T1D-EV- and T1D-EV+ groups compared to the healthy controls $(p<0.001$; Table $2)$, and were more reduced in the T1D-EV+ group than in the T1D-EV - group $(p<0.001 ; 31.76 \pm 1.82$ vs. 22.59 $\pm 5.04,4.81 \pm 0.48$ vs. $2.05 \pm 0.26$, and $119.30 \pm 5.85$ vs. $88.07 \pm 6.39$, respectively).

\section{Discussion}

The incidence of childhood T1D is rising in many countries. Environmental factors, especially viruses, appear to be involved in the initiation or the acceleration of the pathogenesis of this disease. EV infections are associ- ated with the initiation of $\beta$ cell destruction [10]. Evidence for this association has been supported by the detection of EVs in the blood [15], pancreas and islets [12], and gut mucosa [16] of patients with T1D. Our study indicated a prevalence of EV infection in the blood of T1D children is $26.2 \%$. Moreover, the frequency of RNA was higher in newly rather than previously diagnosed children, similar to the observation made by Moya-Suri et al. [17].

Metabolic markers include $\mathrm{HbA}_{1 \mathrm{c}}$, as a direct indicator of blood glucose levels, and C-peptide which correlates with insulin secretion. Both of these are used as markers of pancreatic $\beta$ cell destruction [18]. $\mathrm{HbA}_{1 \mathrm{c}}$ showed an observable increase in both $\mathrm{EV}+$ and $\mathrm{EV}-\mathrm{di}$ abetic children. As reported previously, T1D is associated with exacerbated $\beta$ cell destruction and a decreased secretion of insulin. This was also confirmed by C-peptide levels which conversely decreased in both diabetic groups. Furthermore, when isolated human islets are infected with EV, this reduces their insulin content and glucose-stimulated insulin secretion [19]. On the other hand, the role of EV in the inhibition of insulin secretion appears to be initiated by infected $\beta$ cells, and followed by insulitis, impaired insulin secretion, and $\beta$ cell death [20].

Our data revealed a significant increase in the levels of CRP in the T1D patients, with a marked increase in the T1D-EV+ group. CRP is an acute-phase reactant and is elevated in inflammatory states. Russell and Morgan [21] reported that inflammatory responses including elevated CRP were associated with EV-infected and noninfected patients. T1D is now accepted to be a chronic immunoinflammatory disorder. Because it is a disease of inflammation, of both the innate and adaptive immune systems, it is perhaps not surprising that CRP levels become elevated. Chase et al. [22] hypothesized that inflammation, as reflected by elevated CRP levels, can help predict the development of islet autoimmunity or T1D. In addition, Schalkwijk et al. [23] concluded that CRP levels were higher in subjects with T1D than in control subjects. Although the mechanism of the CRP elevation is unknown, it might be related to the activation of macrophages, increased oxidative stress, and/or the induction of cytokines, and there is evidence that all of these may be factors in the etiology of T1D. On the other hand, after viral infection, ROS are produced from activated phagocytes [24], and they mediate cellular injury and activate inflammatory redox-dependent transcription factors, such as NF- $\kappa B$, thereby perpetuating inflammation. The virus-mediated production of ROS or a reduction in an- 
tioxidants can have severe consequences, as $\beta$ cells are more prone to oxidative damage than most other tissues [8]. Additionally, in T1D, the T cell-mediated autoimmune destruction of pancreatic $\beta$ cells is secondary to the primary invasion by macrophages and dendritic cells into the islets. Macrophages/dendritic cells are activated by intercellular ROS from resident pancreatic phagocytes, and by intracellular ROS formed after receptor-ligand interactions via redox-dependent transcription factors such as NF- $\kappa$ B. Activated macrophages/dendritic cells ferry $\beta$ cell antigens to pancreatic lymph nodes, where they trigger reactive $\mathrm{T}$ cells through synapse formation and the secretion of proinflammatory cytokines and more ROS [25]. Therefore, an inability to balance the oxidation with antioxidant enzymes can drive chronic inflammation from both the innate and adaptive arms of the immune response [26].

Antioxidants constitute the defense system that limits the toxicity associated with free radicals. SOD and CAT are considered primary enzymes since they are involved in the direct elimination of ROS. GPx, SOD, and CAT are considered the most crucial antioxidant enzymes. Islets inherently contain only a fraction of enzymatic activity in comparison to the liver, which has the highest abundance of these enzymes [27]. However, $\beta$ cells are particularly sensitive to ROS because they are low in free radical-quenching (antioxidant) enzymes such as CAT, GPx, and SOD [8]. Thus, the capability of oxidative stress to damage mitochondria and ultimately decrease insulin secretion is not surprising [28]. Glucose-induced insulin secretion was also suppressed by hydrogen peroxide, a chemical substitute for ROS. Several studies have suggested that high glucose levels induce mitochondrial ROS, which suppresses the first phase of glucose-induced insulin secretion, at least in part, through the suppression of GAPDH activity [25, 29 ]. Moreover, the induction of antioxidant enzymes protects $\beta$ cells from oxidative damage and possible cell death, thus minimizing the oxidative damage-related impairment of insulin secretion.

Our data indicated a marked decrease in serum levels of the antioxidant enzymes GPx, SOD, and CAT in T1D$\mathrm{EV}-$ and T1D-EV + children compared to in nondiabetic controls. However, a significant increase in CAT activity in the lymphocytes was found in 40 children with T1D compared with the control group. The highest CAT activity occurs in the early course of the disease, followed by a linear decrease and the lowest activity in the chronic course [30]. Mylona-Karayanni et al. [31] examined the possible correlation between oxidative stress param- eters and the adhesion molecules $\mathrm{P}$-selectin and tetranectin, derived from endothelial/platelet activation, in a group of juveniles with T1D. Significantly elevated nitrate/nitrite and lipid hydroperoxide levels, elevated plasma levels of tetranectin and P-selectin plasma, and lower GPx activity were reported in the diabetic children than in the healthy controls. Based on these findings, the authors suggested that decreased antioxidative protection from the overproduction of lipid hydroperoxide and nitrate/nitrite in juveniles with T1D. Additionally, levels of ROS are under tight control due to the protective action of antioxidant enzymes and nonenzymatic antioxidants in normal and healthy cells. There are multiple likely sources of reactive oxygen in diabetes, including glucose autoxidation, the glycation of proteins, the consumption of NADPH through the polyol pathway, and the activation of protein kinase C [32]. Dave and Kalia [33] reported a significant decrease in GPx, CAT, and glutathione, and a significant increase in the concentration of thiobarbituric acid-reactive substances in T1D patients with and without nephropathy compared to in normal healthy individuals. Finally, ROS generated by high glucose levels and other metabolic abnormalities are important in the development of most diabetic complications [34]. Thus, oxidative stress affects every aspect of $\mathrm{T} 1 \mathrm{D}$, and the benefit of redox modulation may be more important than once thought. Optimal treatments may have to incorporate antioxidants with anti-inflammatory agents, such as inhibitors of NF- $\kappa \mathrm{B}$ activation. This therapy should restore the balance between oxidation and reduction, leading to a resolution of inflammation, and thus reduce the autoimmune destruction of the islet $\beta$ cells [25].

\section{Conclusion}

Oxidative molecules appear to be important mediators of $\beta$ cell destruction and T1D. Antioxidant enzyme activities were lower in T1D-EV+ children than in T1DEV- children, and were more reduced in T1D-EV- children than in nondiabetic controls. Protection from EV infection and supplementation with antioxidants can be beneficial in T1D. 


\section{References}

1 Stene LC, Tuomilehto J, Rewers M: Global epidemiology of type 1 diabetes; in Ekoé J-M, Rewers M, Williams R, Zimmet P (eds): The Epidemiology of Diabetes Mellitus. Chichester, Wiley-Blackwell, 2008, pp 355-383.

2 Maha MM, Ali MA, Abdel-Rehim SE, et al: The role of coxsackieviruses infection in children with insulin-dependent diabetes mellitus. J Egyptian Public Health Assoc 2003;78: 305-318.

3 Ismail NA, Abd El Baky AN, Ragab S, et al: Monocyte chemo-attractant protein 1 and macrophage migration inhibitory factor in children with type 1 diabetes. J Pediatr Endocrinol Metab 2016;29:641-645.

4 Drews G, Krippeit-Drews P, Dufer M: Oxidative stress and beta-cell dysfunction. Pflugers Arch 2010;460:703-718.

5 Halliwell B: Free radicals and antioxidants quo vadis? Trends Pharmacol Sci 2011;32: 125-130.

6 Yung LM, Leung FP, Yao X, et al: Reactive oxygen species in vascular wall. Curr Drug Targets Cardiovasc Haematol Disord 2006;6: 1-19.

7 Andreyev AY, Kushnareva YE, Starkov AA: Mitochondrial metabolism of reactive oxygen species. Biochemistry 2005;70:200-214.

$\$ 8$ Dinić S, Grdović N, Uskoković A, et al: CXCL12 protects pancreatic $\beta$-cells from oxidative stress by a Nrf2-induced increase in catalase expression and activity. Proc Jpn Acad Ser B Phys Biol Sci 2016;92:436-454.

9 Sharma V, Kalim SH, Srivastava MK, et al: Oxidative stress and coxsackievirus infections as mediators of beta cell damage: a review. Sci Res Essays 2009;4:42-58.

10 Nair S, Akil A, Craig ME: Enterovirus infection, $\beta$-cell apoptosis and type 1 diabetes. $\mathrm{Mi}$ crobiol Aust 2013;34:153-156.

11 Sarmiento L, Cabrera-Rode E, Lekuleni L, et al: Occurrence of Enterovirus RNA in serum of children with newly diagnosed type1 diabetes and islet cell autoantibody-positive subjects in a population with a low incidence of type 1 diabetes. Autoimmunity 2007;40:540545.
12 Richardson SJ, Leete P, Dhayal S, et al: Evaluation of the fidelity of immunolabelling obtained with clone 5D8/1, a monoclonal antibody directed against the enteroviral capsid protein, VP1, in human pancreas. Diabetologia 2014;57:392-401.

13 Richardson SJ, Willcox A, Bone AJ, et al: The prevalence of enteroviral capsid protein VP1 immunostaining in pancreatic islets in human type 1 diabetes. Diabetologia 2009;52: 1143-1151.

14 Puig, M, Jofre, J, Lucena, F, et al: Detection of adenoviruses and enteroviruses in polluted waters by nested PCR amplification. Appl Environ Microbiol 1994;60:2963-2970.

15 Oikarinen S, Tauriainen S, Hober D, et al: Virus antibody survey in different European populations indicates risk association between coxsackie virus B1 and type1 diabetes. Diabetes 2014;63:655-662.

16 Oikarinen M, Tauriainen S, Oikarinen S, et al: Type 1 diabetes is associated with Enterovirus infection in gut mucosa. Diabetes 2012;61: 687-691.

17 Moya-Suri V, Schlosser M, Zimmermann K, et al: Enterovirus RNA sequences in sera of schoolchildren in the general population and their association with type 1 diabetes-associated autoantibodies. J Med Microbiol 2005; 54:879-883.

18 Kaneko K, Satake C, Yamamoto J, et al: Case of idiopathic type 1 diabetes with subsequent recovery of endogenous insulin secretion despite initial diagnosis of fulminant type 1 diabetes. Endocr J 2017;64:369-374.

19 Roivainen M, Rasilainen S, Ylipaasto P, et al: Mechanisms of coxsackievirus-induced damage to human pancreatic beta-cells. J Clin Endocrinol Metab 2000;85:432-440.

20 Petzold A1, Solimena M, Knoch KP: Mechanisms of beta cell dysfunction associated with viral infection. Curr Diab Rep 2015;15:73.

21 Russell MA, Morgan NG: The impact of antiinflammatory cytokines on the pancreatic $\beta$-cell. Islets 2014;6:e950547.

22 Chase HP, Cooper S, Osberg I: Elevated Creactive protein levels in the development of type 1 diabetes. Diabetes 2004;53:2569-2573.

-23 Schalkwijk CG, Poland DCW, van Dijk W, et al: Plasma concentration of C-reactive protein is increased in type 1 diabetic patients without clinical macroangiopathy and correlates with markers of endothelial dysfunction: evidence for chronic inflammation. Diabetologia 1999;42:351-357.
24 Xie B, Zhou JF, Lu Q, et al: Oxidative stress in patients with acute coxsackie virus myocarditis. Biomed Environ Sci 2002;15:48-57.

25 Delmastro MM, Piganelli JD: Oxidative stress and redox modulation potential in type 1 diabetes. Clin Dev Immunol 2011;2011:593863.

26 Gloire G, Legrand-Poels S, Piette J: NF- $\mathrm{kB}$ activation by reactive oxygen species: fifteen years later. Biochem Pharmacol 2006;72: 1493-1505.

27 Lei XG, Vatamaniuk MZ: Two tales of antioxidant enzymes on beta cells and diabetes. Antioxid Redox Signal 2011;14:489-503.

28 Lu HT, Chin S, Ya WC, et al: Arsenic induces pancreatic cell apoptosis via the oxidative stress-regulated mitochondria-dependent and endoplasmic reticulum stress-triggered signaling pathways. Toxicol Lett 2011;20:1526.

29 Sakai K, Matsumoto K, Nishikawa T, et al: Mitochondrial reactive oxygen species reduce insulin secretion by pancreatic beta-cells. Biochem Biophys Res Commun 2003;300:216222

30 Zivić S, Vlaski J, Kocić G, et al: The importance of oxidative stress in pathogenesis of type 1 diabetes - determination of catalase activity in lymphocytes of diabetic patients. Med Pregl 2008;61:458-463.

-31 Mylona-Karayanni C, Gourgiotis D, Bossios A, et al: Oxidative stress and adhesion molecules in children with type 1 diabetes mellitus: a possible link. Pediatr Diabetes 2006;7:5159.

32 Golbidi S, Badran M, Laher I: Antioxidant and anti-inflammatory effects of exercise in diabetic patients. Exp Diabetes Res 2012; 2012:941868.

33 Dave GS, Kalia K: Hyperglycemia induced oxidative stress in type- 1 and type- 2 diabetic patients with and without nephropathy. Cell Mol Biol 2007;53:68-78.

34 Kowluru RA, Chan PS: Oxidative stress and diabetic retinopathy. Exp Diabetes Res 2007; 4:43603. 